\title{
'|||||||||||||||||||||||||||||||||||||||||||||||||||||||||||||||||||.
}

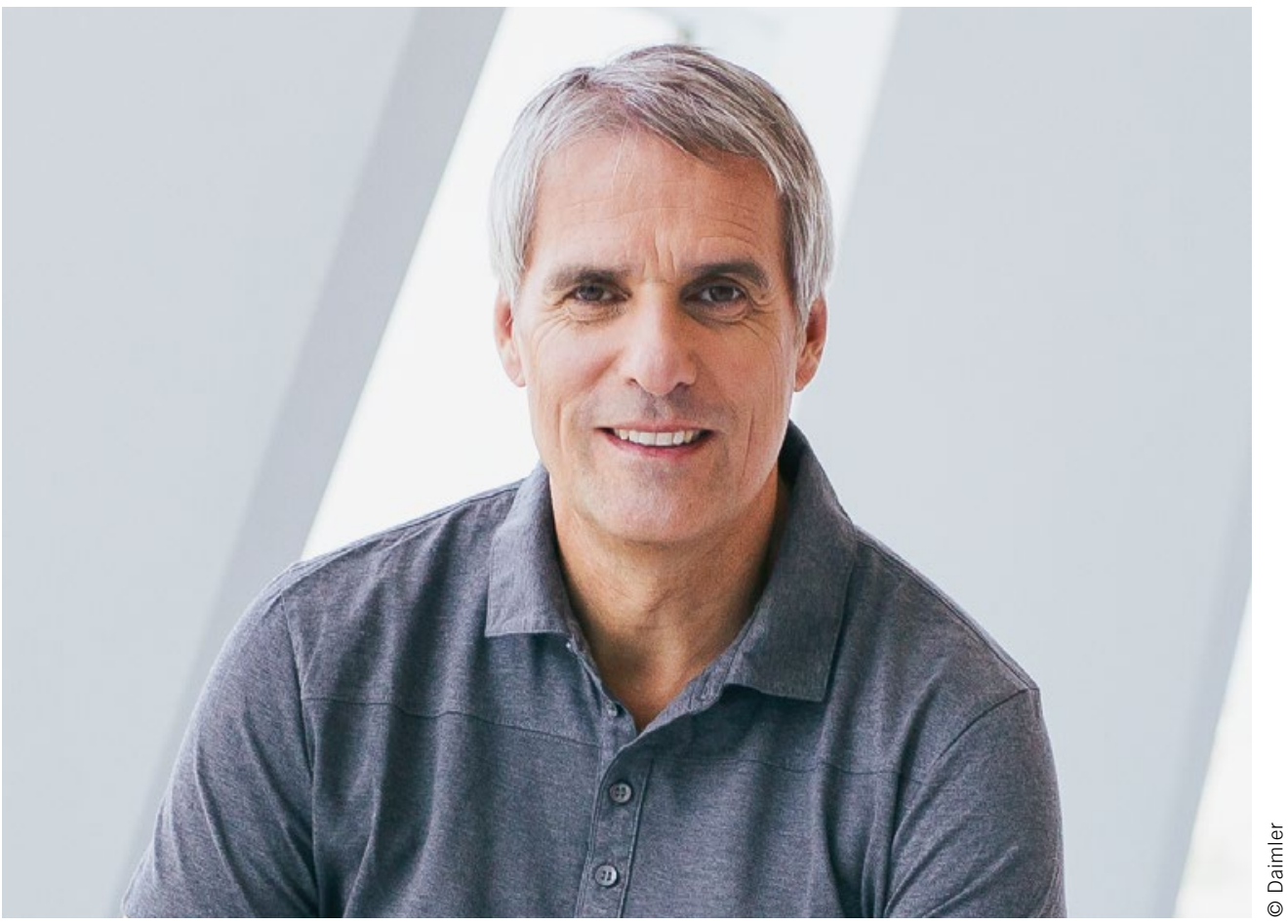

Dipl.-Ing. Wilfried Porth Member of the Board of Management of Daimler AG, Human Resources and Director of Labor Relations, Mercedes-Benz Vans

\section{Setting Sail - Opportunity in Course Changes}

Imagine that you are intending to sail to a port you've never visited before. What would you do? Plan the trip before you leave, measure the wind speed and direction, plot your course, lash the tiller, then do nothing further, and after the time needed for the trip had passed check whether you had reached your destination? Probably not. You would be more likely to make some general calculations and adjust your course from time to time.

It is precisely this ability to respond quickly and independently to changing conditions that is known in a business context as agility. I believe it has made a major contribution to Daimler's success. Agile working speeds up the pace of innovation and increases competitiveness in a complex, volatile environment.

My point is that Daimler has around 290,000 employees from more than 160 nationalities and the entire automotive industry is undergoing a period of upheaval. Digitization, connectivity, electrification, autonomous driving, the shared economy, and mobility apps such as car2go and moovel are all transforming the industry in previously unimagined ways. Our aim is to play an active role in shaping these changes. With our corporate strategy, which has the four key themes of "Connected, Autonomous, Shared \& Service, and Electric Drive" (Case), we are on the right track and are focusing increasingly on new ways of working together.
The characteristic features of agile working include significant freedom to design your own work and considerable responsibility. This type of cooperation requires a new form of management. In contrast to more authoritarian approaches, managers in agile teams are increasingly taking on the role of coaches who support their team, help it to develop, and create a framework for independent action.

For example, in the field of development this means drawing up a clear description of specific product characteristics, functionality, and customer experiences without knowing what the finished product is. In this type of environment, employees need effective guidance that allows them plenty of freedom to act, make use of their own resources, and take the necessary decisions so that they can achieve the next goal independently. This involves a combination of autonomy and coordination with the relevant stakeholders.

Managers at Daimler are learning to hand over control and transfer more responsibility for decision-making to the members of their teams. This requires a great deal of trust on both sides. Sailors know that it makes no sense to sail directly toward their destination. Sailing is the art of keeping your eye on your objective and using the wind to get there, even if it is blowing from the side or changing direction. 